\title{
Martin Neher
}

Wesen und Wirken der Weisheit in der Sapientia Salomonis 


\title{
Beihefte zur Zeitschrift für die alttestamentliche Wissenschaft
}

\author{
Herausgegeben von \\ Otto Kaiser
}

Band 333

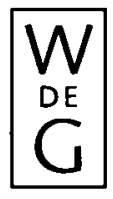

Walter de Gruyter · Berlin · New York 
Martin Neher

\section{Wesen und Wirken der Weisheit in der Sapientia Salomonis}

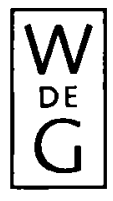

Walter de Gruyter - Berlin · New York 
(0) Gedruckt auf säurefreiem Papier, das die US-ANSI-Norm über Haltbarkeit erfüllt.

\section{ISBN 3-11-017880-X}

\section{Bibliografische Information Der Deutschen Bibliothele}

Die Deutsche Bibliothek verzeichnet diese Publikation in der Deutschen Nationalbibliografie; detaillierte bibliografische Daten sind im Internet über http://dnb.ddb.de abrufbar.

(C) Copyright 2004 by Walter de Gruyter GmbH \& Co. KG, D-10785 Berlin.

Dieses Werk einschließlich aller seiner Teile ist urheberrechtlich geschützt. Jede Verwertung außerhalb der engen Grenzen des Urheberrechtsgesetzes ist ohne Zustimmung des Verlages unzulässig und strafbar. Das gilt insbesondere für Vervielfältigungen, Übersetzungen, Mikroverfilmungen und die Einspeicherung und Verarbeitung in elektronischen Systemen.

\section{Printed in Germany}

Einbandgestaltung: Christopher Schneider, Berlin

Druck und buchbinderische Verarbeitung: Hubert \& Co., Göttingen 
Für Angelika 
